Oscar Asuilar Vidal.

\title{
DON DIEGO BARROS ARANA
}

\section{II}

ㅍiㄱ)

URANTE estos diez años de laborar en el principal establecimiento de la capital, Barros Arana no dejó de preocuparse de otras actividades intelectuales, en los momentos que le dejaban libres las obligaciones escolares. En 1863, lo vemos tomar parte activa en la fundación de un diario de carácter liberal, cuya dirección tuvieron los hermanos Amunátegui, y que servía a la oposición liberal-conservadora. Barros Arana colaboró allí hasta el momento en que este perí́dico, llamado El Independiente, arrojó su careta y pasó a servir únicamente los intereses conservadores. No debemos olvidar que fué este órgano de publicidad uno de los que más atacó la labor de don Diego cuando era Rector del Instituto. Barros Arana fué tres veces al parlamento: en 1867 , en 1870 y en 1888 ; pero no manifestó nunca las dotes políticas que pudieran haberse esperado de una persona de la cultura de él. Hombre franco, sincero, leal a sus ideas, de una sola pieza, no podía estar bien dentro de las triquiñuelas de la política.

Al poco tiempo de haberse hecho cargo del Rectorado del Instituto, y cuando la nación se iba a encontrar pronto en un serio conflicto con España, publicó uno de sus más interesantes y acabados estudios del período de los descubrimientos: me refiero a la Vida de Hernando de Magallanes. Según Mitre,

era lo mejor que se había escrito sobre este célebre viajero y lo mejor que había escrito Barros Arana sobre historia y geografía, por la armonía del conjunto, el severo gusto literario que ha presidido su composicion, y la exactitud de las noticias históricas y geográficas que contiene, bebidas en fuentes.puras y en documentos poco conocidos o inéditos. Es, en fin, un libro que se puede leer por placer por via de sólida instrucción.

(1) Véase el número 68 de Alenea. 
La opinión del historiador argentino refleja fielmente el valor y la importancia de este escrito de Barros Arana. Hasta 1864 no existía un estudio serio y completo de Magallanes; la obra del historiador chileno vino a suplir este abandono en que se había dejado al descubridor lusitano, y es su valor histórico tan importante, que en 1881 la Real Academia de Ciencias de Lisboa la hizo traducir y editar en portugués. El encuentro de nuevos documentos ha modificado sólo parcialmente algunos pequeños detalles de la obra, pero subsiste como un libro de primer orden sobre esta materia. Con motivo del cuarto centenario del descubrimiento del Estrecho de Magallanes, en 1920, don José Toribio Medina ha publicado un erudito trabajo sobre Magallanes y su vida, como sabe hacerlo este investigador.

\section{ACTRVIDADES DESPUES DE LA SALIDA DEL} INSTITUTO

Desde su retiro del Instituto en 1873, Barros Arana se entregó de lleno a sus estudios favoritos, dedicando todos sus momentos, ya a la redacción de una revista, a la crítica de algún libro nuevo, ya a sus labores de historiador concienzudo y honrado. Su gabinete de trabajo donde su primitiva biblioteca ha alcanzado a la enorme suma de diez mil volúmenes, es el rincón predilecto del erudito. Rodeado de cuanto aparato puede poseer un hombre de ciencia (barómetros, telescopios, microscopios, etc.), trabaja en su escritorio desde temprano en medio de la tranquilidad y el silencio de su casa y sólo sale al medio día para dictar sus clases en el Instituto, a las cuales conserva especial cariño. En su escritorio acostumbra a escribir en una mesa sencilla, costumbre que conservó hasta sus últimos años, época en que por su edad, escribía sentado sobre una poltrona, extendiendo el papel sobre las rodillas, rodeado de libros de consulta que formaban montones en completo desorden. Llegaba al Instituto siempre con anticipación, para charlar con sus colegas que tan pronto lo veían aparecer en la sala de profesores o en los patios, lo rodeaban con cariño y admiración. Era un charlador ameno, de fácil palabra, y como poseía profundos conocimientos en las más variadas materias, que lo colocaban en una situación especial de prestigio, era sumamente interesante para cuantos lo trataban poder cultivar amistad con él. Nunca faltaban sus amigos predilectos: Philippi, Amunátegui, Vicuña Mackenna, o sus discípulos-favoritos: Letelier, Manuel Barros Borgoño, Bulnes, Juan Diego Tagle, Ignacio Carrera Pinto y otros. 
Su sed de saber era insaciable y su espíritu estaba en tal forma metodizado que durante sus horas de trabajo nada lo distraía. Se había acostumbrado a escribir diariamente y esa costumbre había llegado a ser un hábito que no lo abandonó sino en las postrimerías de su vida. El caso de la Historia $\mathrm{Ge}$ neral de Chile es típico: escribió por lo menos una hoja diaria de esta obra durante veinte años ininterrumpidos. Sin embargo este fué el único hábito que no abandonó. Estaba tan inmaterializado que podía dejar fácilmente cualquier pequeño vicio o costumbre. Siéndole recomendado por su médico, su sobrino don Manuel Barros Borgoño, que abandonara el cigarro, lo dej6 sin la menor dificultad después de haber sido toda la vida un entusiasta por el tabaco.

Sin embargo sus enemigos fueron hasta su voluntario retiro a interrumpir la tranquilidad de su ostracismo político. En 1874 varias veces en la Cámara el nombre de Barros Arana fué traído a las discusiones con el consabido propósito de atacar al reformador liberal. El señor don José Clemente Fabres, abogado y profesor, vino haciendo una serie de cargos a la persona de don Diego entre los cuales el más grave se refería al negocio que le reportaba al autor del Proceso de Pedro de Valdivia la venta de sus textos de enseñanza. Barros Arana tuvo entonces que salir a defenderse.

Aunque debiera dejar pasar desapercibidos todos los cargos que el señor Fabres ha pretendido formular contra mí, hay uno que necesita una contestaciór. En la última sesión de la Cámara de Diputados el señor Fabres ha dicho que con los textos que he escrito para la enseñanza, he logrado formarme una renta superior a la de un Ministro de Estado, esto es, mayor de $\$ 7,500$. En realidad, y por más que el señor Fabres pretenda otra cosa, no creo que esta aseveración importe un reproche, porque a nadie puede acusarse de recoger el provecho pecuniario de su trabajo. El señor Fabres que tiene tanta ciencia teológica, debe saber que no es pecado vender los libros que uno escribe.

Pero el señor Fabres sufre un engaño respecto a mí. Ni los textos de enseñanza, ni todos los libros que he escrito me han producido un solo centavo de utilidad. Por el contrario me han obligado a gastos muy considerables en compra de libros, en copias de manuscritos y muchas veces en costo de impresión.

Después de esta polémica, publica Barros Arana durante este período de su salida del Instituto dos importantes obras histórica-biográficas: el Elogio a don Miguel Luis Amunátegui, que debía completar más tarde con motivo de la muerte de este hombre público, y la Biografía de don Claudio Gay.

Al acercarse la elección de Presidente de la República las miradas de un gran número de los hombres liberales de nuestro 
país se fijaron en 1875 en la persona de don Miguel Luis Amunátegui. Por la claridad de su inteligencia, por la extensión de sus estudios, por la perfecta honorabilidad de toda su vida, Amunátegui era para un círculo numeroso de la familia chilena el magistrado supremo que reclamaba la situación política. Barros Arana en esta oportunidad aportó su contingente intelectual en favor de esta candidatura, escribiendo un sencillo, pero severo cuadro de la vida del autor de Los precursores de ba Independencia de Chile.

En 1875, por encargo del consejo de la Universidad, escribió un estudio crítico de la obra de Gay, que es al mismo tiempo una descripción magistral del desenvolvimiento de los estudios de zoología, botánica y de la historia en el período de su iniciación y formación de nuestro país. Este trabajo lo publicó don Diego en la Revista Chilena, revista de carácter literario, artístico y científico, fundada por él y su amigo Amunátegui, y que vivió por espacio de cinco años, ejerciendo una gran influencia en el desarrollo de la cultura del país.

\section{BARROS ARANA DIPLOMÁTICO}

En las postrimeríasdel gobierno de Errázuriz vuelve Barros Arana a actuar en la política, pero ahora lo vemos desempeñándose como diplomático. ¿Cuál fué el papel que correspondió a nuestro hombre? ¿Fué feliz en su misión de diplomático? Si en realidad su actuación no fué brillante, tampoco podríamos afirmar que constituyó un fracaso como lo han aseverado alg unos escritores. A fines del siglo pasado la cuestión de límites con Bolivia y con la Argentina preocupó gravemente a la Cancillería chilena con problemas cuyo origen venía desde el tiempo de nuestra emancipación. En 1876 se colocaron en el tapete de la discusión los derechos de Chile sobre el Estrecho de Magallanes, la Patagonia y Tierra del Fuego, y la cuestión tomó caracteres tan alarmantes que el gobierno chileno decidió enviar un Ministro Plenipotenciario ante la Repúblicas del Plata y el Imperio del Brasil con el objeto de buscar una solución pacífica al conflicto. Nadie mejor que la persona de don Diego Barros Arana para desempeñar este delicada misión. Relacionado desde tiempo atrás con distinguidas familias de la sociedad bonaerense, conocedor profundo de nuestra historia y de los derechos de Chile sobre los terrenos en disputa, hombre de vasta cultura e inteligencia, era, por otra parte, garantía segura de los ideales pacifistas 
que predominaban en las esferas gubernativas para resolver este problema.

Efectivamente, el 27 de Abril de 1876 era nombrado para desempeñar este puesto diplomático; todos sus esfuerzos debían tender a hacer una transacción directa para resolver la cuestión, y en caso de que esto no fuera posible, constituir el arbitraje.

Tocóle a Barros Arana iniciar sus tareas diplomáticas en los momentos de mayor tensión en las relaciones internacionales entre los dos países. La delegación fué recibida en Buenos Aires con las manifestaciones de la mayor alarma y con ataques contra Chile. Se pedía a gritos por las calles el rechazo del representante chileno y parecía inminente un serio conflicto. Don Diego, sin embargo, con su espíritu templado y sereno y sus grandes vinculaciones personales con los hombres de mayor significación en la sociedad de Buenos Aires, inició sus negociaciones con el ardiente deseo de que las relaciones de ambos pueblos continuaran siendo fraternales y pacíficas. Después de numerosas conversaciones con el Presidente de la República Argentina y el Ministro Irigoyen, y de estudiarse numerosas fórmulas, proposiciones y contra proposiciones, ge llegó por fin el 18 de Enero de 1878 al tratado por el cual se debería solucionar la cuestión de límites con la República vecina. Sin embargo, este tratado, por el que se proponía como árbitro al rey de los belgas, fué recibido desfavorablemente por el gobierno de Pinto, pero se insistió en la conveniencia de seguir negociando en el sentido de asegurar a Chile la posesión de todo el Estrecho. Finalmente, tanto el tratado de arbitraje como los protocolos fueron declarados inaceptables, y la misión del historiador chileno quedaba terminada, sin que se hubiera avanzado nada hacia el arreglo amistoso de la cuestión. Farece que este fracaso se debió principalmente al desacuerdo que existía entre el diplomático chileno y el Mínistro de Relaciones señor Alfonso.

En todo caso sería injusto desconocer los patrióticos esfuerzos desplegados por el escritor chileno durante su misión diplomática, su consagración interna al servicio de ella, la sinceridad arraigada de sus convicciones en favor de un arreglo amistoso.

Terminada su misión, en 1878 se dirigía a Montevideo, pasaba en seguida al Brasil y de allí se embarcaba rumbo a Europa. Residió en Francia por algún tiempo y se entregó de nuevo a los estudios. Se retiraba de la lucha diplomática con molestias personales y desengaño de los hombres políticos y del gobierno.

Parece-le decía Mitre en carta dirigida a París-que Ud. se ha re- 
tirado un poco lastimado del combate diplomático en que le tocó tomar parte, y que procura apartar de su mente recuerdos ingratos que pudieran irritar la herida secreta que todavía le duele. Yo le he dicho otras veces que en la batalla de la vida, en que se dan y se reciben golpes, es necesario no dejarse dominar por el sentimiento enervante del desencanto o del indiferentismo sistemático.

Vivió en París entregado a sus investigaciones bibliográficas e históricas. Un grave conflicto en el que se veía envuelta su patria-la guerra del Pacífico-lo hizo pensar que su residencia en la metrópoli francesa estaba próxima a terminar. Efectivamente, a principios del año 1880 ya tenemos a nuestro hombre de vuelta a su tierra y dispuesto otra vez a poner su pluma al servicio de la República. El gobierno de Pinto, viendo la opinión desfavorable y errónea que había en numerosos países sobre el desenvolvimiento de la guerra del Pacífico y la mala impresión que predominaba a causa de la propaganda de los agentes peruanos, decidió hacer publicar el desarrollo de la guerra en forma clara y ordenada y repartir en Europa esta obra para contrarrestar la propaganda enemiga. A don Diego Barros Arana le fué encomendado este trabajo y cumplió acertadamente los deseos del gobierno; a pesar de haber sido esta obra publicada al calor de los acontecimientos, cuando estos se iban produciendo, el trabajo de Barros Arana es de indiscutible mérito como exposición desapasionada de la guerra.

El que lea este libro, no busque en él colorido, emoción, palpitaciones de patriotismo. Conténtese con encontrar verdad inexpugnable, exactitud en los hechos y justicia para apreciar a los adversarios.

La obra de Barros Arana y la Historia de la Guerra del Pacífico de don Gonzalo Bulnes, publicada posteriormente y definitiva sobre la materia, son los dos mejores testimonios que existen para conocer con precisión y exactitud las causas y el desarrollo de este lamentable conflicto de tan funestas consecuencias para las relaciones de dos países que indudablemente debieron haber marchado siempre unidos.

En 1881, puesta nuevamente en discusión la cuestión de límites con Argentina tomó parte activa en la confección del tratado de ese mismo año.

Aquí he podido ayudar eal presidente Pinto-decía don Diego en carta enviada a Mitre-en esta negociación y buscar adhesiones al arreglo amistoso. Hoy me parece que la cuestión está resuelta y que la solución es satisfactoria y definitiva. Pinto ha mostrado en esta ocasión un carácter sólido y una inteligencia superior para vencer la resistencia que ha hallado en el camino 
de la negociación, y que le oponía el patrioterismo de algunos hombres de este país.

Se equivocaba Barros Arana al creer que con el tratado de 1881 con Argentina se iba a poner término definitivo a este gravoso conflicto. El fuego prendió con caracteres alarmantes en 1896, y Barros Arana fué nombrado perito por parte de Chile, en cuya comisión reveló profundos conocimientos de la materia.

Sin embargo la política internacional del país no pudo ser más desgraciada, y no obstante los esfuerzos y la entereza de carácter gastados por Barros Arana para defender nuestros derechos en su calidad de perito, en los momentos en que reinaban en las esferas del gobierno la debilidad, la indecisión e inconciencia, se perdió lo que era nuestro por el tratado y la geografía. El pasís devolvió al perito los aplausos que había negado al diplomático y una aureola de patriotismo circundo su gloriosa frente, ha dicho don Gonzalo Bulnes.

\section{LA OBRA DEFINITIVA DE BARROS ARANA}

Para Barros Arana existían dos sistemas o clases de historia: la historia filosófica que permite observar en un cuadro general y concreto la marcha progresiva de la humanidad y apreciar en su conjunto las leyes morales a que está sometido su desenvolvimiento, y el sistema narrativo o sea la exposición clara y documentada de los hechos en forma natural y metódica. El segundo sistema es el que adopta para escribir su obra, pues cree que la llamada historia filosófica es la última transformación del arte histórico y debe ser precedida del estudio documentado y minucioso de los hechos, y como en Chile en la época en que inició su obra la historia de nuestro país estaba todavía muy incompleta, sigue en este sentido la escuela sustentada por don Andrés Bello y contraria a la razonada y filosófica defendida y practicada por Lastarria.

De acuerdo con este sistema se preocupó primeramente de acumular papeles y documentos por bibliotecas y archivos chilenos y extranjeros, y ya a su regreso de su primer viaje de Europa, tenía todos los antecedentes para iniciar su obra. Circunstancias especiales, hemos visto, le impidieron preocuparse de los estudios de su predilección, pues el gobierno lo llevó a ocupar diversos cargos públicos, primero en la instrucción y después en la diplomacia. Sólo en 1881 se entreg6 decididamente a la confección de la Historia General de Chile. Contaba 
en aquella época 51 años, edad relativamente avanzada, y sin embargo, sin saber siquiera si las fuerzas lo acompañarían hasta el final, se entregó con entusiasmo a trabajar en la formidable historia.

No se me ocultaba - ha dicho más tarde Barros Arana-que la obra que acometía a una edad avanzada debía imponerme una tarea de muchos años que tal vez no me sería dado llenar. Esto, sin embargo, no me arredró un solo instante. Un ilustre sabio que a entradas de la vejez acometía una obra monumental de ciencia y perseverancia, escribía estas líneas para explicar el fundamento de su determinación: $\varsigma$ El que quiere hacer un empleo serio de la vida debe siempre obrar como si tuviera largo tiempo que vivir y arreglarse como si debiera morir próximamente. La primera de estas reflexiones me ha determinado a emprender un trabajo que exigía, cuando yo lo comencé, más años y más salud que las que son de ordinario acordadas.? Yo me repetía estas mismas observaciones cuando en Septiembre de aquel año (1881) escribía las primeras páginas de esta historia, lleno de confianza y resolución de llevarla a término en cuanto de mí dependiera.

Por espacio de treinta años se preocupó de atesorar por bibliotecas y museos extranjeros documentos para la elaboración de su bello ideal y por espacio de veinte años se dedicó a la redacción y confección de la Historia General de Chile. Durante los años consagrados a esta tarea ha escrito, casi sin dejar pasar un día, las páginas de este vasto arsenal de nuestro pasado. Este trabajo constante ha sido para el historiador el principal pasatiempo y alivio de los pesares y amarguras que trae siempre consigo la lucha por la vida. Fué tal vez este trabajo su único consuelo y alivio espiritual. Por fin en 1902 llegó al término de la obra, y si bien es cierto una gran alegría era para el historiador haber dado cima a su trabajo, una gran tristeza invadió su alma al separarse de su fiel compañero de veinte años, del más noble de sus entretenimientos. En busca de un nuevo amigo espiritual y por el deseo de poder satisfacer sus gustos literarios, se dedicó Barros Arana a la elaboración de una nueva obra que bien puede considerarse como la continuación de la Hisioria General de Chile: es el Decenio de Bulnes, su última producción intelectual, con la que el sabio coronó y terminó su gloriosa vida.

El fin fundamental de don Diego al escribir esta Historia General fué utilizar todas las obras y documentos que directa o indirectamente se referían a Chile y hacer con ellas una obra general que viniera a satisfacer las necesidades que existían de poseer un trabajo de esta naturaleza. No pretendió hacer una obra definitiva sino un simple cuadro histórico, bien documentado, expuesto con claridad y sencillez, pues comprendía que a un solo hombre no le es dado realizar un trabajo perfecto 
y acabado. Dentro del plan que se traz6 para la elaboración de su obra adoptó el lenguaje más sencillo y natural, huyendo de todo ropaje literario artificioso.

En toda la obra no he buscado otra cosa-dice Barros Arana al hablar de su historia-que la más absoluta claridad que me era dado alcanzar. En ocasiones he dejado aparte porciones de varias páginas de mis manuscritos para rehacerlas y darles una nueva redacción que me parecía más clara y comprensiva.

Dentro de estas modestas pretensiones, comprendía que su obra a través del tiempo podía ser modificada con el descubrimiento de nuevos documentos e investigaciones, como lo son todas las obras da este carácter, que están expuestas a rehacerse continuamente. Sin embargo, para el tiempo de su publicación creía haber producido una obra de gran mérito y duración. Si más tarde apareciera una nueva obıa más completa que viniera a reemplazarla, por lo menos la Historia General tendría que ser consultada como punto de partida para la futura investigación y como fuente abundante de noticias de primera mano.

Hasta ahora los presentimientos del autor no se han realizado. $\mathrm{Ni}$ ha aparecido la obra que venga a reemplazarla, $\mathrm{r}$ ha sido desmentida o criticada en forma tal que venga a impi dir su consulta. Es un monumento tan sólidamente construid que existirá èternamènte para bien y honra de Chile y Amé rica. La Historia General de Chile es la narración completa de todos los sucesos de carácter civil o militar desde los orígenes hasta 1833, o sea el año de la consolidación política de nuestras instituciones. Abarca, pues, el período Indígena, el Descubrimiento, la Conquista, la Colonia, la Independencia y la vida Republicana hasta la promulgación de la Constitución conservadora. Es una verdadera enciclopedia que comprende los sucesos políticos, militares, industriales, literarios y econ6́micos. No se concreta Barros Arana, como lo asegura en su prólogo, a narrar los hechos, a acumular datos en forma coordinada. Después de narrar los hechos que sirven de fundamento a la historia, el escritor acostumbra dar un vistazo general a la época estudiada en que sintetiza los puntos salientes que merecen llamar más la atención, formando cuadros de gran colorido e interés.

Barros Arana poseyó como ningún otro historiador un conjunto de cualidades que lo colocan a la cabeza de los historiadores americanos. Ni Mitre, ni Sarmiento, ni Restrepo, ni Vicuña Mackenna ni Amunátegui, han poseído la instrucción sólida y la erudición que caracterizó a la obra de don Diego 
Barros. Dedicado desde joven a los estudios históricos consagró su vida entera a la confección de su obra. Su austera imparcialidad, su asombrosa memoria, su fino discernimiento, su libertad de juicio y su prestigio como hombre de ciencia, son reconocidos hasta por sus enemigos. Este conjunto de cualidades morales e in telectuales hicieron de él un excelente historiador, con lo que, además de haber poseído las fuentes más completas, se comprende que haya producido la más sólida y perfecta historia de Chile.

Según ha dicho un historiador, esta obra munumental, concebida bajo un plan tan sencillo, será el fundamento inamovible de la historia futura. El que quiera profundizar cualquier período de nuestra historia o deducir de ella la filosofía que encierra, tiene acopiados allí los elementos de esos estudios, con una base de investigación y de verdad que resistirá a la acción del tiempo. Nunca se dice la última palabra en historia ni considerada como arte ni como filosofía, ni como investigación ni como nada; pero los materiales coordinados en esta grande obra forman la armazón monumental de un edificio que tiene la solidez del bronce.

Como claramente lo ha dicho el autor de la Histbria General, sólo ha intentado escribir una historia narrativa, sin pretensiones filosóficas ni críticas; indudablemente pudo haberla hecho después de reconstruir nuestro pasado hasta con lujo de detalles. El mejor que nadie estaba en condiciones de hacerlo, pero al parecer tampoco sentía gran inclinación por este género de historia. ¡Cuán interesante habría sido que Barros Arana hubiera juzgados los hechos del pasado no solamente con el críterio de los hombres de la Conquista y de la Colonia sino también con el criterio del hombre razonador y crítico del siglo XIX!

Cree Barros Arana que el sistema filosófico y crítico se dirige a una minoría, y en cambio el sistema narrativo llega hasta el mayor número de lectores. Quizá en esta apreciación haya algo de exagerado. Desde luego, la Historia General por su misma extensión es y ha sido inaccesible para ese gran número a quien quien creía dirigir su obra el maestro. ¿No estamos viendo que sólo un reducido número de estudiosos puede lanzarse a la lectura de este monumento? Estamos en el siglo de la síntesis; los hombres, por sus múltiples ocupaciones, desean hoy más que nunca conclusiones y generalizaciones. De todas las obras que tratan de la personalidad del gran corso, creo que pocas han sido leídas con más entusiasmo y por mayor cantidad de lectores que el Napoleón de Emil Ludwig. La historia del judío. 
alemán en un solo volumen tha reemplazado con exceso los extensos trabajos escritos durante el siglo XIX sobre el gran Emperador. Es indudable, también, que este éxito obtenido por Ludwig se debe principalmente al nuevo estilo dramatizado de la historia empleado en el último tiempo por algunos escritores. Entonces hacia allá debemos marchar, toda vez que han sido agotados nuestros archivos: hacia la confección de obras que lleguen al gran público y que den a conocer a la mayoría de los chilenos la historia y el desenvolvimiento de nuestra cultura nacional.

Para Barros Arana, además, la historia no sólo debe dar a conocer los hechos pasados sino que debe deducir de ellos las lecciones que interesen a la humanidad. Debe, en una palabra, educar a la humanidad, dar lecciones de moral y de patriotismo. Cualquier persona que haya leído la historia con cierto detenimiento podrá haber observado que son tantos los casos en que se atropella a la moral y se pisotean las leyes que a nuestro juicio la historia no siempre puede considerarse como profesora de moral y de patriotismo. El estrecho concepto nacionalista de la historia, por otra parte, no podrá servir nunca para educar a los pueblos. Mientras exista este concepto estrecho del papel que le cabe desempeñar a la historia, es imposible que la educación vaya a obtener algo en favor de uno de los más grandes ideales: la paz, por ejemplo. Para establecer la paz en el mundo es fundamental sustituir en la educación de la historia de los pueblos el estrecho nacionalismo por una enseñanza más amplia, más internacional, que venga a unir a las naciones en una verdadera confraternidad.

Uno de los méritos indisputables de la obra de Barros Arana es habernos revelado la verdadera personalidad de O'Higgins y San Martín. Hasta la época de la publicación de su obra la tendencia carrerina había aplastado por una serie de prejuicios a la figura de O'Higgins. La rehabilitación de estas dos personalidades ha sido proseguida por Vicuña Mackenna, Mitre y Bulnes: La parte más completa es sin lugar a dudas el período de la independencia. Las nuevas investigaciones de algunos historiadores chilenos han venido a mostrar la debilidad de aquellos capítulos dedicados a la colonia. Se comprende también que los capítulos referentes a la conquista y la independencia pueden completarse si se toma en cuenta que Barros Arana no pudo utilizar la documentación española del siglo XIX. Es indudable también que los párrafos referentes a los orígenes de los pueblos americanos sean susceptibles de trasformación, ya que nuestro historiador se valió de fuentes anti: 
quísimas y el estudio de la prehistoria americana ha progresado en forma tal que esta ciencia queda como una de las que han sufrido mayores transformaciones.

Puede considerarse que la Historia General de Chile, aparte algunas otras pequeñas observaciones, es un monumento histórico que será la fuente obligada de consulta de nuestros investigadores y la obra literaria y científica que honra a Chile en el extranjero, pues su reputación ha pasado los límites de nues tro país. La historia de nuestros antepasados ha sido reconstruída en casi su totalidad, ya por un Barros Arana o un Lastarria, por un Crescente Errázuriz o un Amunátegui, ya por un Vicuña Mackenna o un Gonzalo Bulnes. Hace falta ahora hacer revivir este pasado con el colorido, la dramaticidad o el estudio psicológico de un Ludwig o de un Maurois, al mismo tiempo que es indispensable hacer una historia crítica y filosófica de los siglos XIX y XX.

\section{SUS ULTIMOS AÑOS Y SU MUERTE}

Sin abandonar por un instante sus actividades literarias o sus trabajos en la Universidad, demostrando un dinamismo verdaderamente admirable, al acercarse la Revolución Barros Arana inicia una ardiente campaña política con motivo de las dificultades que se estaban produciendo entre el presidente Balmaceda y el Congreso. Llegada la crisis, don Diego, no obstante haber recibido del Gobierno numerosas distinciones y un premio de veinte mil pesos por su gran Historia, se colocó al lado de los revolucionarios y fué un firme enemigo de la dictadura que se creía venir. Pero su actuación política culminó en 1892, después de la Revolución, con motivo de la gran Convención del partido liberal. Allí, como en anteriores circunstancias, se mostró como el más celoso guardián de las libertades públicas.

En este año vemos también al escritor actuar en sus estudios favoritos. Con motivo del Cuarto Centenario del Descubrimiento de América, la Universidad de Chile celebró una sesión solemne para conmemorar este importante acontecimiento. Barros Arana, con la preparación que le era característica, pronunció en esta ocasión un erudito y novedoso discurso que se publicó en un número extraordinario de los Anales de la Universidad de ese año, junto con otros trabajos salidos de su pluma sobre literatura colombina.

- Desde hacía tiempo se venía sintiendo la necesidad entre 
los profesores universitarios de llevar a la más alta magistradura de la Instrucción Pública a un hombre de méritos y prestigios para que terminara de una vez por todas la influencia de la politiquería dentro de las aulas del Claustro Pleno. En 1893, después de una reñida lucha, se abrió paso y triunfó la candidatura de don Diego Barros Arana para Rector de la Universidad. Con esto se hacía un acto de estricta justicia y de reconocimiento a la labor desarrollada én la enseñanza pública por Barros Arana.

Los que hemos sido primero sus discípulos-decía don Valentín Letelier con motivo de la elección del nuevo rector-, más tarde sus auxiliares, nos sentíamos obligados a tributarle este homenaje, porque después de haber dirigido durante treinta años el desarrollo de la enseñanza como consultor obligado de todos los gobiernos, juzgábamos que ya había ganado por' sus propios esfuerzos el derecho a ser elegido como Rector de la Universidad.

En verdad, ningún otro chileno se encontraba en las circunstancias de don Diego Barros Arana. Sus reconocidos méritos lo colocaban con sobrado derecho en el primer puesto para ocupar tan digno lugar. Era un acto de reparación nacional y de entereza cívica. Sin embargo, no dejó de haber una fuerte oposición en los bandos clericales. La reacción, que lo había arrojado del Instituto, que le había cerrado el paso durante muchos años a la Rectoría, no podía ahora dejar de agotar sus últimas energías en contra de la candidatura Barros e hizo todo lo posible por desprestigiar la persona del venerable anciano. En la Universidad, donde se dió la lucha, la mayoría de los profesores, sin embargo, decidieron hacer justicia y lo eligieron por un gran número de votos para que ocupara el primer lugar en la terna.

Bien pronto probó lo acertado que había sido su elección, pues desde el primer día imprimió un gran impulso a la transformación y progreso de nuestra educación.

Hacía poco que había asumido las altas funciones de Rectorado Universitario cuando ya tomaba bajo su patrocinio las radicales reformas pedagógicas que se habían acordado desde 1889 y que por diferentes causas no se habían realizado hasta entonces. Bajo su impulso vigoroso se reformaron de núevo los programas y los horarios, se generalizó la adopción del plan de estudiós concéntricos, se adelantó con prudencia y perseverancia la renovación del personal docente y en una palabra la instrucción secundaria toda entró de lleno en un período de rejuvenecimiento, animada por un soplo fecundo de vida.

Desempeño este cargo por espacio de un período. En 1897 por oposición del gobierno no fué reelegido, a pesar de que el Claustro Pleno de la Universidad lo colocó dos veces seguidas en pri- 
mer lugar de la terna que debía pasar al Presidente de la República. ¿Qué razones tuvo el gobierno para oponerse a la reelección de Barros Arana para el cargo de Rector? No sabemos, pero razones políticas de mucho peso deben haber existido cuando se atajaba el avance de un reformador de personalidad tan pura como era la de Barro's Arana.

En 1902 con motivo de cumplir don Diego la edad de setenta y dos años se hizo un homenaje público al respetable representante de nuestra cultura nacional. El Ateneo de Santiago, en sesión solemne del 17 de Agosto, le rindió un tributo cariñoso y elocuente en la Aula Magna de la Universidad con asistencia de una selecta concurrencia. Los discursos, a cargo de don Santiago Aldunate Bascuñan, don Valentín Letelier y don Jorge Huneeus, hicieron notar las relevantes cualidades morales e intelectuales del festejado, y la prensa toda, sin distinción de colores políticos, rindió al mismo tiempo el tributo que con justicia se merecía el educador, el historiador y el perito. Ya anteriormente había recibido el reconocimiento de algunas instituciones extranjeras como el Instituto Histórico y Geográfico del Brasil y la Real Academia Española que lo hicieron su miembro correspondiente.

El último libro salido de la pluma de Barros Arana fué Un Decenio de la Historia de Chile, publicada en los años 1905 y 1906 , un año antes de su muerte, con lo cual demostraba que hasta el último momento conservó la lucidez de su inteligencia y el entusiasmo por la literatura histórica.

El Decenio de Bulnes, como hemos dicho, puede ser consisiderado como la continuación de la Historia General de Chile, con lo cual su obra llegaría hasta mediados del siglo pasado. No puede decirse que la obra esté totalmente acabada, no obstante las numerosas y bien meditadas noticias que encontramos en la historia de esta administración. El fin de este libro es poner de manifiesto que en el decenio de 1841 a 1851 el país probó que estaba preparado para la libertad, y que cada vez que en ese período hubo restricción autoritaria la paz pública sufrió quebrantos: o lo que es lo mismo, que la libertad ya aseguraba el orden y el autoritarismo ya provocaba la revuelta.

En las postrimerías de su vida, a un acto noble y generoso dedicó todo su dinamismo característico; como para endulzar su ancianidad. Con su solo esfuerzo quiso honrar la memoria de los amigos y de los ciudadanos levantando un monumento a los hermanos Amunátegui en el principal paseo de la capital. Ya, desde hacía algunos años, había iniciado una activa campaña en favor de la erección de la estatua que se habían gana- 
do con justicia estos escritores y el público correspondió desinteresadamente a esta iniciativa. En 1906, sin necesidad de que el gobierno interviniera oficialmente, Barros Arana inauguraba a nombre del pueblo el monumento que hoy día se alza frente a la Universidad.

Una cruel enfermedad en sus últimos días le impidió la lectura, lo que lo impresionó profundamente. El doctor Sierra que lo atendió hasta en sus últimos momentos con el cuidado que siente un padre hacia su hijo, recibió de él palabras de gratitud.

Quisiera vivir para manifestarle mi agradecimiento-le decía antes de morir-, pero no lo voy a poder hacer. Cuide a su viejo amigo que ya se va.

Fué maestro hasta la ahora postrera, porque para darnos una última lección de santidad y consecuencia en el caos de abjuraciones y debilidades en que vivimos, falleció con la integridad de sus convicciones y con la soberana solemnidad del justo. Un sacerdote que lo visitaba le hablo de la justicia de Dios y él le dijo:

Si Dios es justo, como Ud. lo dice, yo estaré-a su lado en el otro mundo, porque he cumplido como hombre de bien todos mis deberes en este.

Así se fué una conciencia limpia el 5 de Noviembre de 1907. Vivió una época y fué símbolo de ella.

\section{O N C L US I O N}

Con toda justicia se ha colocado a la cabeza de los historiadores chilenos a don Diego Barros. Escritor fecundo, erudito y honrado, usó su pluma para reconstruir el edificio de nuestro desenvolvimiento nacional. Pero además debe ser considerado como el primer humanista de la segunda mitad del siglo XIX, así como lo fué de la primera don Andrés Bello. Fué en la instrucción pública donde demostró todo su cariño y su entusiasmo. El profesorado no es una carrera que produzca dinero en Chile; es un apostolado, una profesión noble llena de sacrificios. En don Diego Barros el amor a la enseñanza no se confundía con ningún interés personal. Fué profesor del Instituto Nacional hasta en los últimos días de su vida. Voy al Instituto, decía, por cariño al establecimiento, no por amor al dinero; ganaba treinta y sicte pesos mensuales. Antes como hoy no 
se tenía conocimiento del verdadero valor del trabajo del magisterio y al parecer no es mucho lo que hemos adelantado.

Ya como profesor, como Rector del Instituto y de la Universidad o como autor de textos didácticos, demostró haber sido el mejor orientado de los educadores de Chile y el que habiendo escrito menos sobre teoría de la educación ha hecho más en la práctica por el desarrollo y transformación de la enseñanza. No menos bríllante fué el papel que desempeñó como defensor de nuestros derechos como perito en la cuestión de límites con Argentina. Teniendo que luchar contra una política internadional desorientada y débil, fué el más hábil ciudadano que supo con voluntad y energía defender nuestros legítinos derechos en este enojoso conflicto.

Pero donde se destaca con caracteres especiales la personalidad de don Diego, es en su vida moral. En su vida privada, digna y ejemplar, una cualidad es la que nos ha llamado más la atención: su honradez. Honradez en sus convicciones y en mantener su conducta por el camino que le señalaba su conciencia, honradez profesional e intelectual, honradez en sus sentimientos para mantenerlos hasta en sus últimos instantes.

Hemos visto cómo desde la juventud esgrimió su pluma en defensa del liberalismo, de acuerdo con su ideología, y es admirable cómo hasta en la vejez cuando su cuerpo se doblaba por el peso de los años conservó la lealtad a sus ideas y la valentía suficiente para escribir aquella admirable página llena de pasión y acerba crítica contra la dictadura que en esos momentos acababa de hacerse trizas ante la roca Tarpeya del civismo chileno.

La insensata y criminal tentativa-decía en 1891 Barros Arana-de poner al país el gobierno de una vergonzosa dictadura después de más de medio siglo de vida constitucional, y de sostenerlo por el establecimiento de un régimen de terror, de violencias, de persecuciones y de sangre desconocido en nuestro pasado, exigió una resistencia no menos esforzada y penosa que la que tuvieron que sostener nuestros padres para alcanzar la independencia de la patria. Esa resistencia, tan hábilmente dirigida como vigorosamente ejecutada, nos ha vuelto al goce de nuestras antiguas libertades y como un triunfo bi illante ha dejado establecido para el presente y para el porvenir que el pueblo chileno no reconoce más soberano que la ley.

El autor de esta obra, víctima, como tantos miles de ciudadanos de las brutales persecuciones de la dictadura, cree tributar un débil, pero justiciero homenaje de gratitud y de admiración dedicando el presente volumen en que ha consignado los hechos gloriosos que nos hicier on independientes, a los buenos chilenos que, bajo la enseñanza de la libertad y de la Constitución, combatieron y derrocaron la oprobiosa y sangrienta dictadura, ya fuese desde el gobierno, ya en la escuadra, ya en el ejército de tierra, que selló la victoria de nuestras augustas instituciones en las más grandes batallas de que ha sido teatro el suelo chileno. 
20. Donosa, Ricardo: Barros Arana Rector del Instituto Nacional. Revista de Educación, 1929. Enero y Febrero. Núms. 2 y 3. Santiago.

21. Espejo, Juan N: Discurso en los Funerales de don Diego Barros Arana. El Mercurio, 7 de Noviembre de 1907.

22. Figueroa, Pedro Pablo: Diccionario Biográfico de Chile. Santiago, 1897.

23. Huneeus Gana, Jorge: Cuadro Histórico de la producción intelectual de Chile. Santiago de Chile, 1910 (pág. 308).

24. Huneeus Gana, Jorge: Labor Literaria de Barros Arana. Homenaje del Ateneo de Santiago, 17 de Agosto 1902. Santiago, 1902.

25. Huneeus G., Jorge: Discurso en los Funerales de don Diego Barros Arana. El Mercurio, 7 de Noviembre de 1907.

26. Monumento a Barros Arana. Editorial de El Mercurio, 27 de Agosto de 1925 .

27. Lastarria, José Victorino: Recuerdos literarios. Santiago 1885.

28 Letelier, Valentín: La lucha por la cultura. Santiago 1895.

29. Letelier, Valentín: La influencia de don Diego Barros Arana en la Instrucción Pública. Homenaje del Ateneo de Santiago, 17 de Agosto de 1902.

30. Letelier, Valentín: Discurso en los Funerales de don Diego Barros Arana. El Mercurio, 7 de Noviembre de 1907.

31. Omer Emeth: Una definición de la historia por el señor Barros Arana. El Mercurio, 7 de Noviembre 1907.

32. Passi García, Ricardo: Diego Barros Arana. Santiago, 1884.

33. Rivas Vicuña, Manuel: Recuerdos de don Diego Barros Arana. El Mercurio, 13 de Abril 1924.

34. Toro, Gaspar: La diplomacia chileno-argentina en la cuestión de límites. Santiago, 1878-1879.

35. Vicuña Mackenna, Benjamín: Biografía de don Diego Barros Arana. Tomo I. (páp.s. 269 a 274) de la Colección de Historiadores de la República. Santiago, 1876. 